JGG 2021;69:32-44

doi: 10.36150/2499-6564-434

\title{
Elderly with COPD: comoborbitidies and systemic consequences
}

Mariano Mollica', Luigi Aronne', Giorgio Paoli ${ }^{1}$, Martina Flora', Grazia Mazzeo', Stefania Tartaglione', Rita Polito², Carmelindo Tranfa', Maria Ceparano ${ }^{1}$, Klara Komici ${ }^{3}$, Gennaro Mazzarella' ${ }^{1}$, Carlo ladevaia ${ }^{1}$

${ }^{1}$ Department of Translational Medical Sciences, University of Campania “L. Vanvitelli"/Hosp. Monaldi, Naples, Italy; ${ }^{2}$ Department of Environmental, Biological and Pharmaceutical Sciences and Technologies, University of Campania "Luigi Vanvitelli", Naples, Italy; ${ }^{3}$ Department of Medicine and Health Sciences "Vincenzo Tiberio", University of Molise, Campobasso, Italy

Chronic obstructive pulmonary disease (COPD) represents a complex respiratory disorder characterized by persistent respiratory symptoms due to chronic airflow limitation caused by exposure to noxious particles/gases with an increased inflammatory response of the airways. COPD is common in older people, with an estimated prevalence of $10 \%$ in the US population aged $>75$ years and is often accompanied by other concomitant chronic conditions that negatively impact prognosis and health status. The aim of this paper is to highlight the relationship between COPD and other comorbidities in elderly population. We focus our attention on the relationship existing between COPD and cardiovascular diseases, lung cancer, obstructive sleep apnoea syndrome, malnutrition/sarcopenia and osteoporosis with particular attention to adipokines, considering that adipose tissue plays a relevant role in the cross-talk between organs.

Key words: aging, COPD, comorbidity, adiponectin

\section{Correspondence}

Komici Klara

Department of Medicine and Health Sciences

"Vincenzo Tiberio", University of Molise, via Giovanni Paolo II 1, 86100 Campobasso, Italy. E-mail: klara.komici@unimol.it

\section{Conflict of interest}

The Authors declare no conflict of interest

How to cite this article: Mollica $M$, Aronne L, Paoli G, et al. Elderly with COPD: comoborbitidies and systemic consequences. Journal of Gerontology and Geriatrics 2021;69:32-44. https:// doi.org/10.36150/2499-6564-434

(C) Copyright by Società Italiana di Gerontologia e Geriatria (SIGG)

\section{(c) (1) (9) $\odot$}

\section{OPEN ACCESS}

This is an open access article distributed in accordance with the CC-BY-NC-ND (Creative Commons Attribution-NonCommercial-NoDerivatives 4.0 International) license. The article can be used by giving appropriate credit and mentioning the license, but only for non-commercial purposes and only in the original version. For further information: https://creativecommons.org/licenses/by-nc-nd/4.0/deed.en

\section{INTRODUCTION}

Chronic obstructive pulmonary disease (COPD) represents a complex respiratory disorder characterized by persistent respiratory symptoms due to chronic airflow limitation caused by exposure to noxious particles/gases with an increased inflammatory response of the airways ${ }^{1,2}$.

COPD global prevalence is about $11.7 \%$ and is responsible for around 3 million deaths annually ${ }^{3}$. Age is often listed as a risk factor for COPD. Chronic obstructive pulmonary disease (COPD) is common in older people, with an estimated prevalence of $10 \%$ in the US population aged $>75$ years ${ }^{4}$. It is unclear if aging leads to COPD or if age reflects the sum of cumulative exposures throughout life ${ }^{5}$. COPD is often accompanied by other concomitant chronic conditions that negatively impact prognosis and health status ${ }^{6,7}$. A large body of literature demonstrates that comorbidities are a widespread problem in COPD patients ${ }^{8-11}$. A review of studies from different countries reports that 86 to $98 \%$ COPD patients have at least 1 other chronic disease with average number of comorbidities per individual ranging from 1.2 to $4.3^{9}$. Furthermore, the prevalence of comorbidities was found especially high in patients with severe COPD ${ }^{10}$. In addition, a recent meta-analysis highlights that 


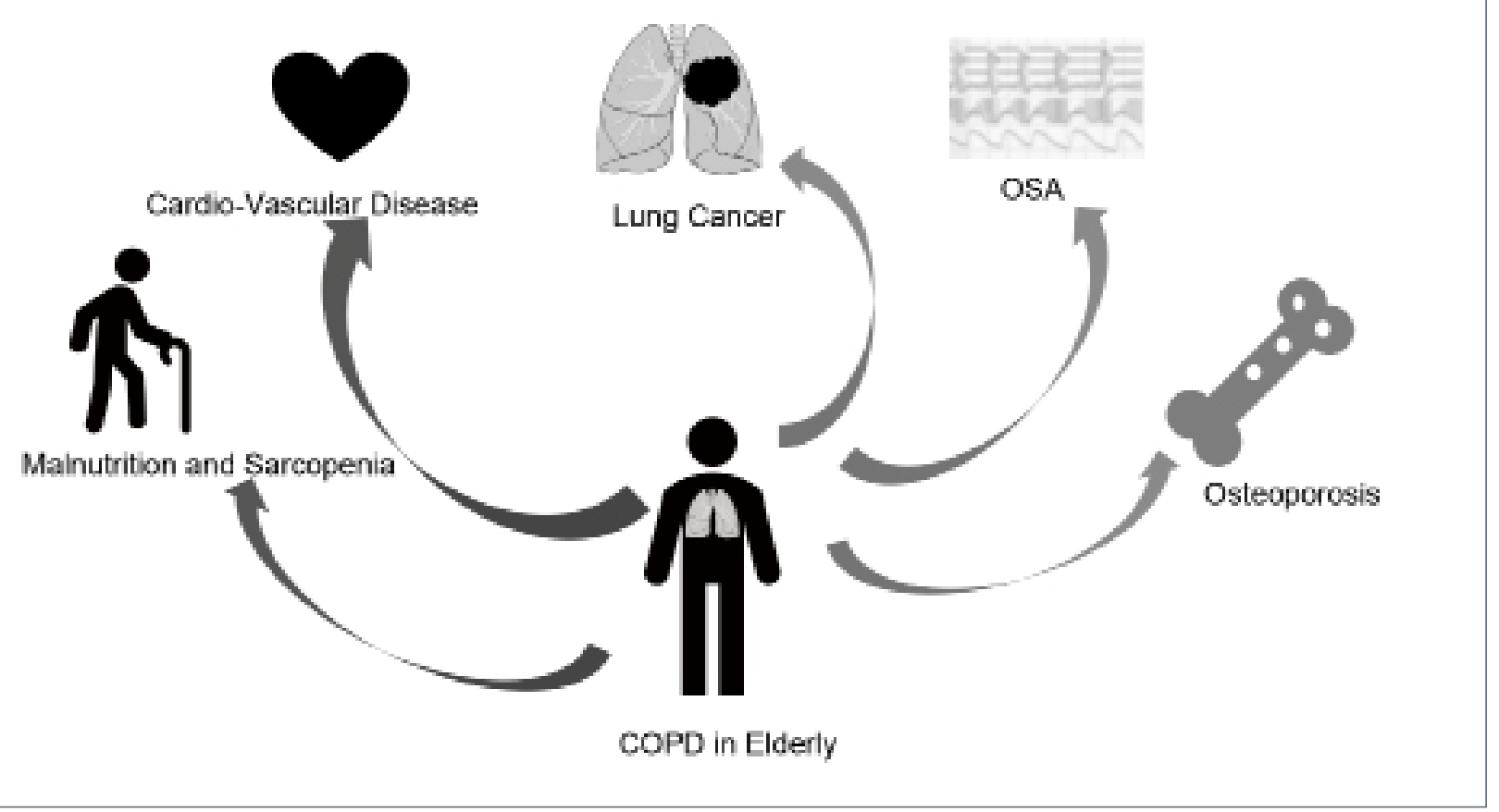

Figure 1. Chronic obstructive pulmonary disease and main comorbidites in elderly patients.

the prevalence of comorbidities in COPD patients is significantly higher in comparison to non-COPD individuals ${ }^{11}$. Some typical comorbidities of COPD are of particular importance for the elderly and require special attention because they are relevant for disease management in these patients ${ }^{12}$. Chronic systemic inflammation state in COPD may have an impact on the natural history of other chronic conditions even if its role is not totally understood ${ }^{13}$. Recent scientific interest has been focusing on biomolecular pathways implicated in cross-talk between organs and their potential in systemic consequences of COPD ${ }^{14-18}$. In this context adipose tissue appears to retain a relevant role ${ }^{19}$.

COPD is associated with the following systemic diseases ${ }^{20}$ :

- cardiovascular diseases: ischemic heart disease, cerebrovascular disease, peripheral artery disease, left and right heart failure, pulmonary hypertension, arrhythmias (atrial fibrillation and flutter), arterial hypertension;

- respiratory tract diseases: obstructive sleep apnea, pneumonia, lung fibrosis;

- metabolic diseases: metabolic syndrome, type ॥ diabetes mellitus, dyslipidemia;

- haematological diseases/coagulopathies: secondary polycythemia, anaemia, venous thrombosis and pulmonary embolism;
- musculoskeletal diseases: muscle dysfunction, muscle wasting, osteoporosis;

- gastro-intestinal diseases: gastro-oesophageal reflux disease, peptic ulcer disease, liver cirrhosis;

- renal diseases: renal dysfunction;

- psychiatric diseases: depression, anxiety;

- cancers: lung, esophageal, pancreatic, breast, and all other cancers.

Comorbidities are inversely correlated with self-reported health status ${ }^{9}$ and the presence of more than three comorbidities impacts quality of life more than lung function ${ }^{21}$. Moreover, the risk of exacerbation and hospitalization is related to the number of comorbidities ${ }^{22}$, as well as the risk of mortality ${ }^{23}$ and total annual cost of the disease ${ }^{24}$.

Polypharmacy, defined as the use of more than 5 or 10 pharmacological agents, is another key concept in the COPD management. In the general population it is associated with multimorbidity ${ }^{25}$ and with an increased risk of adverse drug reactions (ADRs), especially in the elderly ${ }^{26-28}$.

Exacerbation and infectious episodes influence the course of the disease resulting in increased symptom burden ${ }^{29-31}$.

In conclusion, in order to achieve the goal of improved quality of life and survival, the correct management of COPD in elderly should include identification and treatment of all chronic associated conditions. 
In this review we discuss the relationship between COPD and other comorbidities, in elderly population.

\section{COPD AND CARDIOVASCULAR DISEASES}

Cardiovascular diseases (CVD) are the most prevalent comorbidities in COPD elderly patients. Pulmonary hypertension, right ventricular dysfunction, arterial stiffness, systemic hypertension, left ventricular dysfunction, dysrhythmia, chronic heart failure and ischemic coronary disease have higher incidence and prevalence in patients suffering from COPD when compared with healthy population. This is not surprising because the two conditions share common risk factors, such as smoking, physical inactivity and ageing. Systemic inflammation and oxidative stress are centrally involved in the pathophysiology of both COPD and cardiovascular diseases promoting atherosclerosis ${ }^{32}$. The viscoelastic properties of the arteries allow propagation of the pulse wave along vessel walls generated from left ventricular ejection. The speed of this wave is directly linked to arterial stiffness. Early studies demonstrated that arterial stiffness is an independent predictor of cardiovascular accidents in other chronic pathological conditions, such as diabetes, renal failure and systemic hypertension ${ }^{33}$. In individuals suffering from COPD, in contrast to healthy agematched controls, arterial stiffness has been shown to be increased, and correlates with the degree of airflow limitation. The mechanisms responsible for higher arterial stiffness in patients with COPD are largely unknown. The most plausible hypothesis is that, similar to that proposed for other chronic inflammatory condition, arterial stiffness is related to the state of chronic systemic inflammation that follows local (lung) inflammation as a consequence of "spill over" of the inflammatory process into the systemic circulation ${ }^{34}$. Indeed, fibrinogen levels and C-reactive protein are higher in COPD patients than in control subjects ${ }^{35,36}$. However, the possibility that systemic inflammation due to causative factors such as smoking exposure eventually affect the airways, thus leading to inflammatory changes that predispose to COPD, cannot be ruled out. An interesting hypothesis is that both impaired lung function and increased arterial stiffness in COPD are due to the increased susceptibility to degradation of connective tissue, as an expression of premature ageing triggered by smoking exposure. Elastolytic activity by means of metalloproteinases is enhanced in emphysema and atherosclerosis: firstly, elastin degradation leads to loss of alveolar attachments and emphysema; on the other hand, elastin degradation is associated with increased collagen and thicker arteries ${ }^{37}$ in elderly. Hypoxia, commonly observed in advanced stages of COPD, is responsible for vasoconstriction of the pulmonary vascular bed and remodeling with myointimal hyperplasia causing, in turn, pulmonary hypertension and right ventricle hypertrophy and dilation ${ }^{38}$. Wats et al investigated the relationship between lung function, heart size, heart dysfunction and the consequences for 6-min walking distance (6MWD) in patients with COPD in different stages. The results of the study have shown that static hyperinflation (inspiratory-to-total lung capacity ratio [IC/TLC], functional residual capacity, and residual volume) is better related to cardiac chamber sizes than airway obstruction or diffusion capacity. The authors demonstrated that COPD patients with an IC/TLC $<$ or $=0.25$ had a significantly impaired left ventricular diastolic filling pattern and a significantly impaired global ventricular function (expressed as Tei-index) compared with patients with an IC/TLC $>0.25^{39}$. Despite a clear relationship between the above-mentioned illness, results of a study from Macchia and colleagues show that at least $20 \%$ of patients with COPD suffering from left ventricular dysfunction that affects survival, are misdiagnosed ${ }^{40}$. For these reasons the definition of a clear protocol for diagnosis is important for management and follow up of CVD in COPD patients. André $S$ et al. proposed a diagnostic algorithm for CVD evaluation in COPD, suggesting, in stable patients not experiencing an acute exacerbation, a baseline ECG and laboratory test such as Brain type Natriuretic Peptide (BNP) and N-terminal pro-BNP that are sensitive biomarkers of heart failure. Higher levels of BNP are associated with an increase of mortality risk. Dosing serum levels of c-reactive protein (CRP) seems to be useful also in evaluation of CVD; indeed, patients who present both moderate/severe obstruction and higher CRP serum levels have higher risk of ischemic heart disease. Echocardiogram is proposed only if needed after evaluation of symptoms and ECG ${ }^{41}$. Treatment of CVD in COPD patients has changed significantly in the last decade. For a long time $\beta$-blockers were not prescribed in patients with COPD fearing that their use might be responsible for bronchoconstriction. Even after the release of new molecules with higher affinity for $\beta 1$ adrenergic receptors and lower for $\beta 2$ receptors, COPD was still considered by a lot of clinicians a good reason for choosing another type of medication even if less effective. Several observational studies evaluated safety and efficacy of standard dose of $\beta$ blockers in COPD patients, showing that their use is related to a reduction in overall mortality, exacerbation rate and severity. Furthermore, recent studies have demonstrated that $\beta$ blockers could represent the best treatment of hypertension in the COPD subgroup ${ }^{42}$. ESC 
Guidelines suggest that for patients with heart failure and concurrent COPD metoprolol, bisoprolol or nebivolol should be preferred instead of carvedilol ${ }^{43}$.

\section{COPD AND ADIPOKINES}

Recent achievements have changed the biological view about adipocytes functions. White adipose tissue is considered an endocrine source of biologically active substances with local and/or systemic action called adipokines ${ }^{44}$. An inappropriate secretion of adipokines seems to participate in the pathogenesis of obesity-related diseases including endothelial dysfunction, inflammation and atherosclerosis ${ }^{45}$. In particular, the intercorrelation between adipose tissue and lung has become clear; the involvement of leptin and adiponectin has been demonstrated in several lung diseases such as COPD, emphysema, asthma and cancer ${ }^{46-49}$. In fact, through the secretion of adipokines, adipose tissue participates in the regulation of several patho-physiological processes in many organs and tissues. Among the adipokines, adiponectin and leptin are the two most relevant. The biological function of adipokines in lung diseases seems to be mainly related to the inflammatory process ${ }^{50}$. In fact, with specific regard to COPD, a low-grade inflammatory state has been demonstrated. Adiponectin is one of the most abundant circulating adipocytokines, accounting for the $0.01 \%$ of total serum protein. Adiponectin is involved in a wide variety of physiological processes including energy metabolism, inflammation, and vascular physiology. These effects are mediated by two atypical widely expressed seven-transmembrane receptors, AdipoR1 and AdipoR2. Adiponectin has beneficial effects in cardiovascular systems and blood vessels protecting these tissues through the inhibition of pro-inflammatory and hypertrophic responses and stimulation of endothelial cell responses. In addition, growing evidence suggests that adiponectin also exerts a crucial role on vascular endothelium maintaining vascular homoeostasis and being protective against vascular dysfunctions ${ }^{51,52}$. Altogether these findings support the anti-inflammatory role of adiponectin in COPD patients. Previously, we reported higher adiponectin levels in COPD compared to healthy subjects ${ }^{53}$. Furthermore, since adiponectin circulates as three different isoforms (low molecular weight-LMW, medium molecular weight-MMW and high molecular weight-HMW), we investigated the oligomerization state of serum adiponectin. Interestingly, we found for the first time that the adiponectin oligomerization state is altered in COPD; particularly, we observed that the higher levels of adiponectin are associated with a significant and specific increase of
HMW, representing the most biologically active forms. In addition, we demonstrated the presence of AdipoR1 and AdipoR2 with a lower expression of AdipoR2 compared to AdipoR1. Moreover, we demonstrated the expression of both AdipoR 1 and 2 in lung tissues from COPD with non-small cell lung cancer (NSCLC) with a lower expression of AdipoR2 compared to AdipoR1. The important role of adiponectin in patho-physiological conditions of lung is also supported by the modulation of AdipoRs with the down regulation of AdipoR2. The low expression of AdipoR2 may indicate a specific role of this receptor, mainly implicated in adiponectin effects on inflammation and oxidative stress. In addition to the above-mentioned epidemiologic studies, in vitro studies have demonstrated that adiponectin has protective effects against inflammation and the aberrant growth of cancer cells ${ }^{54,55}$. In particular, in a model of lung inflammation, adiponectin is able to reduce damage induced by pro-inflammatory cytokines ${ }^{56}$. Regarding leptin, many studies have reported that leptin provides a link between obesity and lung diseases. It is well known that leptin is a pro-inflammatory mediator in COPD disease. In fact, an increase of leptin in human sera leads to impaired immune responses and facilitates the infection resulting in increased pneumonia severity ${ }^{57}$. Furthermore, the upregulation of migration, inhibition of apoptosis, and increased proliferation are also found in leptin-stimulated airway epithelial cells ${ }^{58}$. In both in vivo and in vitro studies, leptin promoted the expression of the CPLA2 $\alpha$ gene in lung alveolar type II cells via MAPK and NF-кB-activated coactivator p300 ${ }^{59}$. In the lung system, the increased leptin induced cPLA2 $\alpha / C O X-2$ expression and leukocyte infiltration via the NADPH oxidase-dependent production of ROS. These evidences confirm the inflammatory effect of leptin in the lung and in particular in COPD, and suggest that leptin plays a central role in the pathogenesis of COPD in obese subjects.

\section{COPD AND LUNG CANCER}

COPD and lung cancer are closely related, based on shared main risk factors. Ongoing research is exploring the linking mechanisms, such as premature lung aging, genetic predispositions, common pathogenic factors or intracellular pathways or epigenetics factors ${ }^{60}$.

Certainly, lung cancer is five times more common in smokers with COPD than in those with normal lung function ${ }^{61,62}$ and COPD is an independent risk factor for lung carcinoma, mostly for squamous cell carcinoma ${ }^{63}$. Despite the advances in early identification and in the therapeutic management of both COPD and lung cancer the underlying networking mechanisms are far from 
being well established resulting in poor prognosis ${ }^{64-69}$. Many epidemiological studies have showed that emphysema and air flow obstruction are both involved as risk factors for lung cancer incidence and death, but their relative roles have not been fully clarified. Firstly, both chronic respiratory obstructive diseases and lung cancer are common in the aging lung ${ }^{70}$.

The risk of developing cancer increases with age and is higher in COPD patients over 40 years old ${ }^{71,72}$. Lung function decline with age is faster and premature in COPD due to oxidative stress and telomere shortening. Free radicals, such as RNOS, are exogenous (cigarettes) and also endogenous, generated by mitochondrial respiration. This is typically dysfunctional in cancer ${ }^{73}$. All these mechanisms lead to DNA damage, lipid peroxidation and amino acid oxidation. These evidences validate the free radical hypothesis of aging, which suggests RNOS accumulation determines DNA damage and cell transformation to malignant ones if not correctly repaired (point mutations, single and double stand breaks, DNA-crosslinking) ${ }^{74}$.

RNOS can also inactivate tumor suppressors and apoptosis factors, allowing tumor growth to continue. RNOS are also intracellular signals activating, directly or indirectly, inflammatory and proliferative pathways (such as ROS receptor/proto-oncogene ROS1- and PI3K-mTOR pathway, c-Jun N-terminal kinases JNK, dependent mitogen activate protein kinase (MAPK), NF-Kb pathway), upregulating immune and inflammatory genes expression. Furthermore, NO stimulates tumor growth activating vascular endothelial growth factor (VEGF) ${ }^{75}$.

Some studies have showed the correlation between short telomere length and both lung cancer and COPD ${ }^{76}$. Telomeres are repetitive nucleotide sequences that protect the chromosome against the shortening caused by DNA replication. When telomeres arrive at the Hayflick limit and become too short, involving the tumor suppressor proteins p53 and Retinoblastoma protein $(\mathrm{Rb})$, the cell is not able to divide further and goes towards senescence. These mechanisms prevent excessive replication and the risk of generating neoplasms. However, some cells can inactivate Rb and p53 signaling pathways, giving life to a perennial clone that preserve telomere length despite cells divisions. Telomere shortening is also accelerated by smoking, leading more rapidly to replicative senescence, inflammation and emphysema, causing COPD or generating a cancer clone cell ${ }^{77}$. There are also evidences of a familial predisposition to lung cancer and COPD. Some regions in chromosome 6 seem to be involved: CHRNA3, CHRNA5 SNPs (15q), HHIP, FAM13A and HTR4 ${ }^{78}$. The rs7326277TT genotype in VEGFR1 is a locus connected with inflammation, epithelial to mesenchymal transition and tumor growth. Also epigenetic changes can be involved in the development of COPD and cancer. Hypermethylazion of tumor suppressor or gene promoters is common in lung cancer and also hypomethylation of immunomodulatory genes ${ }^{79}$. Methylation of the 5' position of a cytosine residue of tumor suppressor genes (APC, CDKN2, BRCA1, RB, mdm2) induces proliferation. A new prospective will be cluster DNA methylation patterns, corresponding to 3 lung cancer clusters and different carcinogenetic factors ${ }^{80,81}$.

The recent EWAS study has examined the links between gene methylation in COPD and lung cancer, and the result was that methylation and repression of CCDC37 and MAP1B is associated with COPD and lung cancer ${ }^{82}$.

Cigarette smoke reduces the activity of HDAC2 at protein and mRNA level, inducing a lower inactivation of inflammatory genes. The role of mRNAs and miRNAs is not totally clear. MiR-1 seems to be linked to cigarette smoking-related diseases and is downregulated in skeletal muscle ${ }^{83}$. Other miRNA involved are miR-21 and miR-146a, this one is particular because may downregulate inflammation and proliferation ${ }^{84}$. Considering all the common elements between COPD and lung cancer, chronic inflammation in COPD could serve as a bridge for the development of lung cancer. The inflammatory context influences the cancer microenvironment and cytokines signaling which may ${ }^{85-87}$ interfere with therapy including Immunecheck points inhibitors ${ }^{88,89}$. The overexpression of NF-kB in chronic inflammation is the first mediator of inflammation-induced carcinogenesis. It induces IL-1, IL-6, IL-8, TNF $\alpha$ and also many factors of the cell cycle, such as cyclines D1, D2, D3, E1 and various CDKs, and suppresses p53. Cigarette smoke induces an aberrant expression of growth factors (as EGF) which increase the rate of cell division and repair lung damage. This leads to epithelial-mesenchymal transition (EMT), a process linked to both cancer and COPD. COPD patients live in a hypoxic condition (air trapping, emphysema, airflow flow obstruction) and this is a trigger to activate hypoxia inducible factor (HIF) $1-\alpha$. This factor is induced also by the cancer hypoxic environment, regulating glycolisis, telomerase activation, inhibition of apoptosis and cell differentiation. The emphysematous microenvironment could also encourage lung cancer growth. The alveolar capillary destruction and poor vascularization, typical of emphysematous areas, could lead to expression of genes of hypoxia-inducible factor- $1 \alpha$ or could induce to mutation in genes such as TP53 and CDK2N2A. Therefore, the cells may avoid apoptosis and become able to transform into a cancerous focus. With the diffusion of computed tomography $(\mathrm{CT})$, it is now possible to detect the severity of emphysema ${ }^{90}$. The method for evaluating emphysema 
is fundamental and it appears that visual detection has a more important clinical correlation despite the automated computer analysis. The cancer results correlated only to visually-detected emphysema ${ }^{91}$. Contrary to common belief, several studies have noticed a possible inverse relationship between incidence of lung cancer and the severity of air flow obstruction. Older age, low BMI, DLCO < 80\% predicted and GOLD Stages I and II (even small differences in FEV1 \% predicted) seem to be the real independent risk factors for the development of lung cancer ${ }^{92}$. It is hypothesized that smokers, who develop milder disease, have a dysfunctional immune system enabling the cancer progression. Instead patients with severe COPD have a more aggressive immune system that can block cancer growth. It appears that CD4+ T-cell Th1 and Th17, CD8+ T-cell increase with the disease progression ${ }^{93}$. Furthermore CD8+ cells create expression of the inhibitory receptors PD1, TIM3 and PDL1 and this may explain why patients with COPD Lung cancer display longer survival with anti-PD1 antibodies ${ }^{94}$.

Smokers with mild and moderate air flow obstruction, DLCO $<80 \%$ predicted or CT detected emphysema, have a particular risk for development of lung cancer and could represent the right target for a screening program. Lung functional parameters are also crucial in the pre-surgical evaluation of patients undergoing lung resection for lung cancer ${ }^{95,96}$. The United States Preventive Services Task Force (USPSTF) recommends low-dose CT since $2014{ }^{97}$. A novel score to predict lung cancer risk for patients with COPD is the COPDLUCSS, characterized by four parameters: age $>60$, $\mathrm{BMl}<25 \mathrm{~kg} / \mathrm{m}^{2}$, pack-years $>60$, presence of radiological emphysema; with a total range from 0 to 10 points. Low-risk patients (scores 0-6), high risk ${ }^{7-10,98}$. Available data show that lung cancer screening in COPD patients, using proper scores, may improve early diagnosis of lung cancer, reducing late stage diagnosis ${ }^{99}$. Regarding the impact on mortality, screening mild and moderate COPD significantly reduces the incidence; therefore, active screening is justified in these patients ${ }^{100}$. However, the benefits of a screening program are perhaps not so relevant because there are other concomitant causes of death caused by COPD ${ }^{101}$.

\section{COPD AND OSAS}

The relationship between obstructive sleep apnoea syndrome (OSAS) and COPD has recently been a matter of great interest.

This relationship is complex, with common risk factors and hypothesized mutual causal links. Continuous positive airways pressure (CPAP) is the gold standard for the treatment of OSAS and plays a major role in the therapeutic management of the COPD-OSAS overlap syndrome. OSAS is characterized by recurrent episodes of partial or complete upper airways collapse with various respiratory events such as flow limitations, snoring, obstructive hypopneas and apnoeas. The upper airways patency - influenced by the activity of pharyngeal constrictor and dilator muscles - is therefore critical in the pathogenesis of the OSAS patients' nocturnal events. The nocturnal respiratory events and their cyclic recurrence cause oxyhaemoglobin desaturations with neurophysiological consequences like sleep fragmentation and morning sleepiness ${ }^{102}$. Long term negative effects on cardiac and cerebrovascular homeostasis are of great importance too. They are the reason why OSAS patients have a higher risk of arterial hypertension, arrhythmias, myocardial ischaemia and stroke ${ }^{103}$. In COPD patients sleep is frequently shorter and of poor quality. The cause has been traced back to the COPD itself and to pharmacologic polytherapy. During COPD patients' sleep, the ventilation physiological reduction is enhanced with a change in the ventilatory pattern and in the blood gases levels, configuring the typical pattern of the NOD (nocturnal oxygen desaturation) ${ }^{104}$. The suspected causative mechanisms are: reduced chemosensitivity of the respiratory nuclei, weakened contraction of the respiratory muscles, increased peripheral resistance, reduced residual functional capacity (RFC) enhanced by the supine position. The patients already hypoxemic awake, like those hypercapnic awake, show higher levels of nocturnal oxygen desaturation. Such events of oxygen desaturation are more intense during stage 3 of NREM sleep and during REM sleep ${ }^{105}$. For many years now the relationship between OSA and COPD is acknowledged under the title of Overlap Syndrome. About 15\% of COPD patients suffer from concurrent OSA. Such patients show lower levels of nocturnal haemoglobin saturation and a higher risk of chronic cor pulmonale and arterial hypertension. Overlap syndrome patients present hypercapnia earlier when compared with COPD patients and analogue functional impairment without OSA. The therapeutic approach to the overlap syndrome consists of simultaneous treatment of both pathologies. Machado et al. observational study performed on patients suffering from COPD and OSA demonstrated a longer survival in the patients accepting CPAP as OSA treatment ${ }^{106}$. Marin et al. proved that the Overlap Syndrome patients had a higher risk of severe COPD exacerbation and hospitalization ${ }^{107}$. The discontinuation of a smoking habit and good inhaled therapy compliance are mandatory for the success of treatment. Oxygen therapy alone is not recommended in patients with COPD and OSAS especially in those with awake hypercapnia but can be of help in the 
resolution of the residual desaturation after correction of the apnoeas ${ }^{108}$. CPAP remains the gold standard for treatment of OSA patients. BIPAP (biphasic positive airway pressure, BIPAP) is useful in patients with a low compliance to CPAP and in those with hypercapnia ${ }^{109}$.

\section{COPD-RELATED MALNUTRITION AND SARCOPENIA}

COPD is known to negatively affect the elder patients' nutritional status, being able to produce specific morbid conditions as malnutrition and sarcopenia whose assessment is relevant for a correct management of the pathology.

Malnutrition can be diagnosed referring to the latest and widely used criteria proposed by the European Society for Clinical Nutrition and Metabolism (ESPEN) in 2015. According to the ESPEN consensus, patients are classified as malnourished when they have a body mass index $(\mathrm{BMI})<18.5 \mathrm{~kg} / \mathrm{m}^{2}$ or between 18.5 and $22 \mathrm{~kg} /$ $\mathrm{m}^{2}$, combined with a free fat mass index $(\mathrm{FFMl})<17 \mathrm{~kg} /$ $\mathrm{m}^{2}$ for men and $<15 \mathrm{~kg} / \mathrm{m}^{2}$ for females. The simultaneous presence of elevated serum CRP concentrations (CRP $\geq 5 \mathrm{mg} / \mathrm{dL}$ ), and/or reduced serum concentrations of albumin (albumin $<3.5 \mathrm{~g} / \mathrm{dL}$ ), combined with malnutrition, is a criterion for the diagnosis of cachexia or disease-related malnutrition with inflammation ${ }^{110}$.

Sarcopenia is another nutritional phenotype to consider in the evaluation of COPD patients. Broadly accepted diagnostic criteria for sarcopenia have been developed by the European Working Group of Sarcopenia in Older People (EWGSOP), who have proposed an algorithm based on loss of skeletal muscle mass (SM) plus reduced strength and/or performance ${ }^{111}$.

Low muscle mass can be evaluated performing a multifrequency BIA (body impedance assessment) in standardized conditions (i.e. ambient temperature between 23 and $25^{\circ} \mathrm{C}$, fast $>3 \mathrm{~h}$, empty bladder, supine position for at least 10 min before starting the measurement). The skeletal muscle mass index (SMI) cut-off values are $\leq 8.50 \mathrm{~kg} / \mathrm{m}^{2}$ for men and $\leq 5.75 \mathrm{~kg} / \mathrm{m}^{2}$ for women ${ }^{112}$. Low muscle strength can be assessed by handgrip strength (HGS), a proxy index of overall muscle strength, measured with a digital hand-held dynamometer and expressed in kg. Patients are asked to perform a maximum voluntary isometric contraction of finger flexor muscles ${ }^{113}$. Physical performance is measurable by a $4-\mathrm{m}$ gait speed test, as described by Kon et al. ${ }^{114}$. Patients are asked to walk down a $4 \mathrm{~m}$ flat, unobstructed course at their usual speed. Low walking speed is defined as walking slower than $0.8 \mathrm{~m} / \mathrm{s}$.

In the literature the prevalence of COPD-related malnutrition is quite variable due not only to the characteristics of patients (stages of the disease, exacerbations, etc.), but also to the use of different diagnostic approaches. De Blasio et al., using the diagnostic criteria for malnutrition proposed by the 2016 ESPEN consensus, reported an average prevalence of $19.8 \%^{115-118}$ that was higher in the more advanced stages of disease, as already reported in previous papers using other diagnostic approaches ${ }^{119}$. The prevalence of sarcopenia, referring to EWGSOP criteria is reported to vary between the 14.5 and $25 \%{ }^{120}$. Several factors have been shown to participate in the multifactorial aetiology of COPD-related malnutrition and sarcopenia including systemic inflammation, a well-known condition associated with COPD ${ }^{121}$. A recent study by Byun et al. ${ }^{122}$ demonstrated, performing a multivariate analysis, that higher hsTNF $\alpha$ was a significant determinant for the presence of sarcopenia. In the same study, muscle strength assessed by HGS and muscle mass (MM) measured by skeletal muscle mass index (SMMI) showed significant correlation with levels of IL-6 and hsTNF $\alpha$. Such results are noteworthy since all patients had stable, not exacerbated COPD. The notion that systemic inflammation contributes to skeletal muscle wasting in COPD patients is supported by the fact that many proinflammatory cytokines can adversely influence the skeletal muscle mass through the activation of muscle proteolysis and the inhibition of protein synthesis in elderly ${ }^{123}$. Experimental studies have shown that inflammatory markers, such as increased blood levels of TNF- $\alpha$, promote muscle wasting by enhancing the activity of the ubiquitin proteasome pathway or by inducing apoptosis ${ }^{124}$. Other aetiological factors of COPD-related malnutrition and sarcopenia are: chronic hypoxia inducing a reduction in muscle mass probably as a result of the interaction of several molecular mediators such as inflammation, hypoxia inducible factor-1 signaling pathway, oxidative stress, and reduced oxidative enzyme capacity and capillary numbers; hypercapnia, which may worsen during exacerbations, negatively affecting the muscle mass through acidosis as it enhances ubiquitin-proteasome proteolytic system activity and/or through a reduction in protein anabolism; cigarette smoking; drugs, especially systemic corticosteroids; physical inactivity ${ }^{125,126}$. The evaluation of the nutritional status should be of primary importance in the management of COPD considering the following evidences: a low free fat mass index strongly correlates with the mortality in normal-weight COPD patients; sarcopenia is associated with loss of mobility, falls, osteoporosis, poor quality of life (QOL) due to fractures, hospitalization, and death ${ }^{127}$.

Various therapeutic approaches have been proposed regarding COPD-related malnutrition and sarcopenia. Pulmonary rehabilitation $(\mathrm{PR})$ in elderly patients with COPD 
has already been proven beneficial with high-quality evidence. PR is a multidisciplinary integrated treatment program that contains exercise, education, behaviour change, and nutritional therapy. Exercise refers to a planned and repetitive activity for a specific purpose over a certain period of time, with a definition different from that of physical activity. Exercise is also one of the most effective ways to improve sarcopenia. The EWGSOP noted that exercise with a primary goal of improving physical performance, strength and muscle mass is fundamental for sarcopenia treatment ${ }^{128}$. Exercise in sarcopenia is largely composed of resistance exercise, aerobic exercise, and balance and flexibility exercises. Intensive resistance training by elderly patients effectively increases muscle function and mass. Nutritional support plays a key role too. Significant improvements in mid-arm muscle circumference, FFMI, 6MWT, respiratory muscle strength, and overall health-related QOL have been reported with nutritional supplementation in malnourished patients with COPD ${ }^{129}$. The PROT-AGE study group recommended a protein supply of 1.0 to $1.2 \mathrm{~g} / \mathrm{kg}$ for healthy elderly people and 1.2 to $1.5 \mathrm{~g} / \mathrm{kg}$ for elderly people with chronic or acute disease ${ }^{130}$. Some medicines and supplements currently available in clinical practice may be useful for patients with sarcopenia and COPD. Vitamin $\mathrm{D}$ is thought to play an important role in muscle metabolism, and it was recently reported that vitamin D plays a role in skeletal muscle mass and muscle strength. When vitamin D was deficient, atrophy of type II muscle fiber was confirmed. It was also reported that muscle performance was improved when the 25-hydroxy-vitamin D concentration was more than $60 \mathrm{nmol} / \mathrm{L}{ }^{131}$. Beta-hydroxy- $\beta$-methylbutyrate $(\mathrm{HMB})$ is a metabolite of leucine and is often used as a nutritional supplement during muscle training. $\mathrm{HMB}$ increases protein synthesis through protective and anti-catabolic effects. It also stabilizes muscle cell membranes and weakens proteolytic pathways. This process can contribute to a reduction of sarcopenia. In chronic diseases including COPD, HMB was effective in preventing muscle loss, and it was reported that the usual dose of $3 \mathrm{~g} /$ day HMB was effective with no definite side effects ${ }^{132,133}$. Selective Androgen Receptor Modulator has recently been shown to be effective in the prevention and treatment of muscle wasting in clinical trials in cancer patients ${ }^{134}$, and clinical trials are underway for other diseases such as COPD.

\section{COPD AND OSTEOPOROSIS}

Elderly affected by COPD experience an increased risk of developing osteoporosis. The prevalence of osteoporosis in COPD is between 4 and 59\%, depending on the diagnostic method used, the population studied, and the severity of underlying respiratory disease. A recent literature survey performed in COPD patients by Graat-Verboom and colleagues showed that a number of risk factors for osteoporosis can be identified, including low body mass, disease severity, use of corticosteroids, age and female gender ${ }^{135}$. The presence of emphysema is a relevant factor, often associated with lower BMl and reduced BMD, and may represent a clinical phenotype at high risk of osteoporosis ${ }^{136}$. Another central item in patients affected by COPD is the use of systemic GCSs which play a major role in increasing bone fracture incidence and have deleterious effect on BMD. A meta-analysis made by van Staa et al. ${ }^{137}$ showed a strong inverse correlation between bone density and total cumulative dose of GCSs. A significant correlation was also found between the daily dose of GCSs and the risk of fractures, even with low oral doses of Prednisone as 2.5 to $5 \mathrm{mg}$. In addition to this, there are several studies that demonstrated how patients receiving oral GCSs are more likely to develop one or more vertebral fractures ${ }^{138}$. On the other hand, the effects of inhaled corticosteroids (ICSs) on bone loss and fracture risk are less clear. Several studies reported mild effect of high doses of ICSs on bone turnover ${ }^{139}$, moreover, a recent sub-analysis of $\mathrm{TORCH}$ study conducted on 658 patients revealed no significant effect of ICSs on BMD over the course of 3 years ${ }^{140}$. On the basis of this, the treatment of osteoporosis in patients affected by COPD aims to reduce the risk of fracture and this goal can be achieved with pharmacological and non-pharmacological intervention (such as smoking cessation and physical activity). Pharmacological interventions consist of calcium and vitamin D supplementation and anti-resorptive therapy. Tang et al. in 2007, performed a systematic review to evaluate the effects of Calcium alone or in combination with vitamin $\mathrm{D}$ on osteoporotic fractures and BMD in adults aged 50 years or older, stating that combination therapy is best for fracture prevention when Vitamin $\mathrm{D}$ alone is ineffective in preventing fractures ${ }^{141}$. Other drugs commonly used for the prevention and treatment of osteoporosis are bisphosphonates; several studies confirm their protective effect on bones, but few studies have specifically addressed the effect of antiresorptive agents in COPD. A randomized controlled trial performed by Smith et al demonstrated a significant improvement in lumbar spine BMD through daily intake of alendronate ${ }^{142}$.

\section{CONCLUSIONS}

COPD is a very heterogeneous condition, common in older people. Whether aging leads to COPD or age itself reflects cumulative exposures throughout life leading to 
COPD remains matter of debate. Concomitant chronic conditions are relevant and negatively impact prognosis and health status. The role of ageing on development of comorbidities in COPD is increasingly recognized and the number of comorbidities is associated to the risk of exacerbation, hospitalization and mortality in COPD. Systemic inflammation affects natural history of COPD and is implicated in concomitant chronic conditions such as cardiac failure, osteoporosis, diabetes and peripheral artery diseases. Bio-molecular pathways implicated in cross-talk between organs and their potential in systemic consequences of COPD are under investigations. Growing scientific interest has been recently focused on Adipose tissue that appears to exert a relevant role.

As COPD comorbidities in elderly are complex a multidisciplinary approach to provide a comprehensive management to a multifaceted disease is required.

\section{References}

1 GOLD Executive Committee. Global strategy for the diagnosis, management and prevention of chronic obstructive pulmonary disease (2017 REPORT) (https://goldcopd.org).

2 Mazzarella G, Lucariello A, Bianco A, et al. Exposure to submicron particles (PM1.0) from diesel exhaust and pollen allergens of human lung epithelial cells induces morphological changes of mitochondria tonifilaments and rough endoplasmic reticulum. In Vivo 2014;28:557-61.

3 Adeloye D, Chua S, Lee C, et al. Global and regional estimates of COPD prevalence: systematic review and meta-analysis. J Glob Health 2015;5:020415. https://doi. org/10.7189/jogh.05.020415

4 Akinbami LJ, Liu X. Chronic obstructive pulmonary disease among adults aged 18 and over in the United States, 1998-2009. NCHS Data Brief 2011;63:1-8.

5 Paolisso G. COPD in elderly patients. Journal of Gerontology and Geriatrics 2016;64:117-8.

6 Libertini G, Corbi G, Cellurale M, et al. Age-related dysfunctions: evidence and relationship with some risk factors and protective drugs. Biochemistry (Mosc) 2019;84:1442-50.

7 Vestbo J, Hurd SS, Agusti AG, et al. Global strategy for the diagnosis, management and prevention of chronic obstructive pulmonary disease. GOLD Executive summary. Am J Respir Crit Care Med 2013;187:347-65.

8 Noteboom B, Jenkins S, Maiorana A, et al. Comorbidities and medication burden in patients with chronic obstructive pulmonary disease attending pulmonary rehabilitation. J Cardiopulm Rehabil Prev 2014;34:75-9.

9 Putcha N, Puhan MA, Hansel NN, et al. Impact of comorbidities on self-rated health in self-reported COPD: an analysis of NHANES 2001-2008. COPD 2013;10:324-32.

10 Testa G, Cacciatore F, Bianco A, et al. Chronic obstructive pulmonary disease and long-term mortality in elderly subjects with chronic heart failure. Aging Clin Exp Res 2017;29:1157-64.
11 Yin HL, Yin SQ, Lin QY, et al. Prevalence of comorbidities in chronic obstructive pulmonary disease patients: a meta-analysis. Medicine 2017;96:e6836. https://doi. org/10.1097/MD.0000000000006836

12 Pedone C. Comorbidities of COPD as a function of age: evidence and practical recommendations. Journal of Gerontology and Geriatrics 2016;64:126-30.

13 Divo M, Cote C, de Torres J, et al. Comorbidities and risk of mortality in patients with chronic obstructive pulmonary disease. Am J Respir Crit Care Med 2012;186:155-61.

14 Conti V, Corbi G, Manzo V, et al. Sirtuin 1 and aging theory for chronic obstructive pulmonary disease. Anal Cell Pathol (Amst) 2015;2015:897327. https://doi. org/10.1155/2015/897327

15 Conti V, Corbi G, Manzo V, et al. SIRT1 activity in peripheral blood mononuclear cells correlates with altered lung function in patients with chronic obstructive pulmonary disease. Oxid Med Cell Longev 2018;2018:9391261. https://.doi. org/10.1155/2018/9391261

16 Flora M, Perrotta F, Nicolai A, et al. Staphylococcus aureus in chronic airway diseases: an overview. Respir Med 2019;155:66-71. https://.doi.org/10.1016/j. rmed.2019.07.008

17 Maniscalco M, Bianco A, Mazzarella G, et al. Recent advances on nitric oxide in the upper airways. Curr Med Chem 2016;23:2736-45.

18 Maniscalco M, Vitale C, Vatrella A, et al. Fractional exhaled nitric oxide-measuring devices: technology update. Med Devices (Auckl) 2016;9:151-60.

19 Faner R, Cruz T, López-Giraldo A, et al. Network medicine, multimorbidity and the lung in the elderly. Eur Respir J 2014;44:775-88.

20 Decramer M, Rennard S, Troosters T, et al. COPD as a lung disease with systemic consequences-clinical impact, mechanisms, and potential for early intervention. COPD 2008;5:235-56.

21 Van Manen JG, Bindels PJ, Dekker EW, et al. Added value of co-morbidity in predicting health-related quality of life in COPD patients. Respir Med 2001;95:496-504.

22 Soler-Cataluna JJ, Martinez-Garcia MA, Roman Sanchez $P$, et al. Severe acute exacerbations and mortality in patients with chronic obstructive pulmonary disease. Thorax 2005;60:925-31.

23 Miller J, Edwards LD, Agustí A, et al. Comorbidity, systemic inflammation and outcomes in the ECLIPSE cohort. Respir Med 2013;107:1376-84.

24 Huber MB, Wacker ME, Vogelmeier CF, et al. Excess costs of comorbidities in chronic obstructive pulmonary disease: a systematic review. PLoS One 2015;10:e0123292. https://.doi.org/10.1371/journal.pone.0123292

25 Corsonello A, Pedone C, Corica F, et al. Polypharmacy in elderly patients at discharge from the acute care hospital. Ther Clin Risk Manag 2007;3:197-203.

26 Johnell K, Klarin I. The relationship between number of drugs and potential drug-drug interactions in the elderly: a study of over 600,000 elderly patients from the Swedish Prescribed Drug Register. Drug Saf 2007;30:911-8. 
27 Corbi G, Gambassi G, Pagano G, et al. Impact of an innovative educational strategy on medication appropriate use and length of stay in elderly patients. Medicine (Baltimore) 2015;94:e918.

28 GBD 2015 Chronic Respiratory Disease Collaborators. Global, regional, and national deaths, prevalence, disability-adjusted life years, and years lived with disability for chronic obstructive pulmonary disease and asthma, 1990-2015: a systematic analysis for the Global Burden of Disease Study 2015. Lancet Respir Med 2017;5:691-706.

29 Giannattasio A, Brunese L, Ripabelli G, et al. Coinfections with influenza virus and atypical bacteria: implications for severe outcomes? Clin Respir J 2018;12:366-7. https:// doi.org/10.1111/crj.12510

30 Bianco A, Parrella R, Esposito V, et al. Severe $A(H 1 N 1)$ associated pneumonia sequential to clamidophila pneumoniae infection in healthy subject. In Vivo 2011;25:825-8.

31 Bianco A, Mazzarella G, Rocco D, et al. FDG/PET uptake in asymptomatic multilobar Chlamydia pneumoniae pneumonia. Med Sci Monit 2010;16:CS67-70.

32 Corbi G, Bianco A, Turchiarelli V, et al. Potential mechanisms linking atherosclerosis and increased cardiovascular risk in COPD: focus on sirtuins. Int J Mol Sci 2013;14:12696713. https://doi.org/10.3390/ijms140612696

33 Boutouyrie P, Tropeano Al, Asmar R, et al. Aortic stiffness is an independent predictor of primary coronary events in hypertensive patients: a longitudinal study. Hypertension 2002;39:10-15.

34 GanWQ, Man SF, Senthilselvan A, et al. Association between chronic obstructive pulmonary disease and systemic inflammation: a systematic review and a meta-analysis. Thorax 2004;59:574-80.

35 Dahl M, Tybjaerg-Hansen A, Vestbo J, et al. Elevated plasma fibrinogen associated with reduced pulmonary function and increased risk of chronic obstructive pulmonary disease. Am J Respir Crit Care Med 2001;164:1008-11.

36 Pinto-Plata VM, Müllerova $\mathrm{H}$, Toso JF, et al. C-reactive protein in patients with COPD, control smokers and nonsmokers. Thorax 2006;61:23-8.

37 Costanzo L, Pedone C, Battistoni F, et al. Relationship between $\mathrm{FEV}_{1}$ and arterial stiffness in elderly people with chronic obstructive pulmonary disease. Aging Clin Exp Res 2017;29:157-64.

38 Watz H, Waschki B, Meyer T, et al. Decreasing cardiac chamber sizes and associated heart dysfunction in COPD: role of hyperinflation. Chest 2010;138:32-8. https://doi. org/10.1378/chest.09-2810

39 Criner GJ. COPD and the heart: when less lung means more heart. Chest 2010;138:6-8. https://doi.org/10.1378/ chest.10-0669

40 Macchia A, Rodriguez Moncalvo JJ, Kleinert M, et al. Unrecognised ventricular dysfunction in COPD. Europ Resp J 2012;39:51-8.

41 André S, Conde B, Fragoso E, et al; GI DPOC-Grupo de Interesse na Doença Pulmonar Obstrutiva Crónica. COPD and Cardiovascular Disease. Pulmonology 2019;25:16876. https://doi.org/10.1016/j.pulmoe.2018.09.006
42 Vanfleteren L, Spruit M, Wouters F, et al. Management of chronic obstructive pulmonary disease beyond the lungs. Lancet Respir Med 2016;4:911-24.

43 Ponikowski P, Voors AA, Anker SD, et al. 2016 ESC Guidelines for the diagnosis and treatment of acute and chronic heart failure: the Task Force for the diagnosis and treatment of acute and chronic heart failure of the European Society of Cardiology (ESC). Developed with the special contribution of. Eur Heart J 2016;37:2129-200.

44 Nigro E, Scudiero O, Monaco ML, et al. New insight into adiponectin role in obesity and obesity-related diseases. Biomed Res Int 2014;2014:658913.

45 Di Zazzo E, Polito R, Bartollino S, et al. Adiponectin as link factor between adipose tissue and cancer. Int J Mol Sci 2019;20. pii: E839. https://doi.org/10.3390/ijms20040839

46 Nigro E, Daniele A, Scudiero O, et al. Adiponectin in asthma: implications for phenotyping. Curr Protein Pept Sci 2015;16:182-7.

47 Bianco A, Mazzarella G, Turchiarelli V, et al. Adiponectin: an attractive marker for metabolic disorders in Chronic Obstructive Pulmonary Disease (COPD). Nutrients 2013;5:4115-25. https://doi.org/10.3390/nu5104115

48 Maio S, Baldacci S, Simoni M, et al.; ARGA Study Group. Impact of asthma and comorbid allergic rhinitis on quality of life and control in patients of Italian general practitioners. J Asthma 2012;49:854-61.

49 Baldacci S, Maio S, Simoni M et al.; ARGA study group. The ARGA study with general practitioners: impact of medical education on asthma/rhinitis management. Respir Med 2012;106:777-85. https://doi.org/10.1016/j. rmed.2012.02.013

50 Perrotta F, Nigro E, Mollica M, et al. Pulmonary hypertension and obesity: focus on adiponectin. Int J Mol Sci 2019;20:912.

51 Bianco A, Nigro E, Monaco ML, et al. The burden of obesity in asthma and COPD: role of adiponectin. Pulm Pharmacol Ther 2017;43:20-5.

52 Corbi G, Polito R, Monaco ML, et al. Adiponectin expression and genotypes in italian people with severe obesity undergone a hypocaloric diet and physical exercise program. Nutrients 2019;11:pii: E2195. https://doi.org/10.3390/ nu11092195

53 Daniele A, De Rosa A, Nigro E, et al. Adiponectin oligomerization state and adiponectin receptors airway expression in chronic obstructive pulmonary disease. Int J Biochem Cell Biol 2012;44:563-9.

54 Nigro E, Stiuso P, Matera MG, et al. The anti-proliferative effects of adiponectin on human lung adenocarcinoma A549 cells and oxidative stress involvement. Pulm Pharmacol Ther 2019;55:25-30.

55 Illiano M, Nigro E, Sapio L, et al. Adiponectin down-regulates CREB and inhibits proliferation of A549 lung cancer cells. Pulm Pharmacol Ther 2017;45:114-20.

56 Nigro E, Scudiero O, Sarnataro D, et al. Adiponectin affects lung epithelial A549 cell viability counteracting TNF $\alpha$ and IL-1B toxicity through AdipoR1. Int J Biochem Cell Biol 2013;45:1145-53. 
57 Ubags ND, Stapleton RD, Vernooy JH, et al. Hyperleptinemia is associated with impaired pulmonary host defense. JCl Insight 2016;1:pii:e82101.

58 Suzukawa M, Koketsu R, Baba S, et al. Leptin enhances ICAM-1 expression, induces migration and cytokine synthesis, and prolongs survival of human airway epithelial cells. Am J Physiol Lung Cell Mol Physiol 2015;309:801-11.

59 Hsu PS, Wu CS, Chang JF, et al. Leptin promotes CPLA(2) gene expression through activation of the MAPK/NFkappaB/p300 cascade. Int J Mol Sci 2015;16:27640-58.

60 Barnes PJ, Adcock IM. Chronic obstructive pulmonary disease and lung cancer: a lethal association. Am J Respir Crit Care Med 2011;184:866-7. https://doi.org/10.1164/ rccm.201108-1436ED

61 Young RP, Hopkins RJ. Link between COPD and lung cancer. Respir Med 2010;104:758-9. https://doi. org/10.1016/j.rmed.2009.11.025

62 Young RP, Hopkins RJ, Duan F. Airflow limitation and histology shift in the national lung screening trial. The NLSTACRIN Cohort Substudy. Am J Respir Crit Care Med 2015;192:1060-7.

63 Papi A, Casoni G, Caramori G, et al. COPD increases the risk of squamous histological subtype in smokers who develop non -small cell lung carcionoma.Thorax 2004;59:679-81.

64 Pilyugin M, Descloux $\mathrm{P}$, André PA, et al. BARD1 serum autoantibodies for the detection of lung cancer. PLOS One 2017;12:e0182356. https://doi.org/10.1371/journal. pone.0182356

65 Zhang YQ, Bianco A, Malkinson AM, et al. BARD1: an independent predictor of survival in non-small cell lung cancer. Int J Cancer 2012;131:83-94. https://doi.org/10.1002/ ijc.26346

66 Rinaldi L, Milione S, Fascione MC, et al. Relevance of lung ultrasound in the diagnostic algorithm of respiratory diseases in a real-life setting: a multicentre prospective study. Respirology 2019. https://doi.org/10.1111/resp.13659

67 Perrotta F, Khiroya R, Russell P, et al. Diagnosis of combined adenocarcinoma small cell lung cancer by endobronchial ultrasound transbronchial needle aspiration. J Bronchology Interv Pulmonol 2019;26:e20-e2. https://doi. org/10.1097/LBR.0000000000000573

68 Fiorelli A, Perrotta F, Mollica M, et al. Endoscopic central airway recanalization to enable first line pembrolizumab treatment in a PD-L1 strongly positive non-small cell lung cancer: a case report. J Cardiothorac Surg 2019;14:50. https://doi.org/10.1186/s13019-019-0862-6

69 Cattaneo F, Guerra G, Parisi M, et al. Expression of formylpeptide receptors in human lung carcinoma. Anticancer Res 2015;35:2769-74.

70 Mollica M, Salvi R, Paoli G, et al. Lung cancer management: challenges in elderly patients. Journal of Gerontology and Geriatrics 2019;67:132-40.

71 Longobardi L, Di Giorgio A, Perrotta F, et al. Bronchial asthma in the elderly patient. Journal of Gerontology and Geriatrics 2016;64:55-65.

72 Kamo K, Katanoda K, Matsuda T, et al. Lifetime and age-conditionl probabilities of developing or dying of cancer in Japan. Jpn J Clin Oncol 2008;38:571-6. https://doi. org/10.1093/jjco/hyn061

73 Caramori G, Adcock IM, Casolari P, e al. Unbalanced oxidant-induced DNA damage and repair in COPD: a link toward lung cancer. Thorax 2011;66:521-7. https://doi. org/10.1136/thx.2010.156448

74 Kryston TB, Georgiev AB, Pissis P, et al. Role of oxidative stress and DNA damage in human carcinogenesis. Mutat Res 2011;711:193-201 https://doi.org/10.1016/j. mrfmmm.2010.12.016

75 Kobliakov VA. Mechanisms of tumor promotion by reactive oxygen species. Biochemistry (Mosc) 2010;75:675-85.

76 Hosgood HD, Cawthon R, He X, et al. Genetic variation in telomere maintenance genes, telomere lenght, and lung cancer susceptibility. Lung Cancer 2009;66:157-61. https://doi.org/10.1016/j.lungcan.2009.02.005

77 Amsellem V, Gary-Bobo G, Marcos E, et al. Telomere dysfunction causes sustained inflammation in chronic obstructive pulmonary disease. Am J Respir Crit Care Med 2011;184:135866. https://doi.org/10.1164/rccm.201105-08020C

78 Schwartz AG, Ruckdeschel JC. Familial lung cancer: genetic susceptibility and relationship to chronic obstructibive pulmonary disease. Am J Respir Crit Care Med 2006;173:16-22.

79 Qiu W, Baccarelli A, Carey VJ, et al. Variable, Methylation is associated with chronic obstructive pulmonary disease and lung function. Am J Respir Crit Care Med 2012;185:37381. https://doi.org/10.1164/rccm.201108-1382OC

80 Sato T, Eri A, Takashi K, et al. Epigenetic clustering of lung adenocarcinomas based on DNA methylation profiles in adjacent lung tissue:its correlation with smoking history and chronic obstructive pulmonary disease. Int J Cancer 2014;135:319-34.

81 Nigro E, Imperlini E, Scudiero O, et al. Differentially expressed and activated proteins associated with non small cell lung cancer tissues. Respir Res 2015;16:74. https:// doi.org/10.1186/s12931-015-0234-2

82 Tessema M, Yingling CM, Picchi MA, et al. Epigenetic repression of CCDC37 and MAP1B links chronic obstructive pulmonary disease to lung cancer. $J$ Thorac Oncol 2015;10:1181-8.

83 Leidinger P, Keller A, Borries A, et al. Specific peripheral miRNA profiles for distinguishing lung cancer from COPD. Lung Cancer 2011;74:41-7. https://doi.org/10.1016/j. lungcan.2011.02.003

84 Esteller M. Non-coding RNAs in human disease. Nat Rev Genet 2011;12:861-74. https://doi.org/10.1038/nrg3074

85 Bianco A, Perrotta F, Barra G, et al. Prognostic factors and biomarkers of responses to immune checkpoint inhibitors in lung cancer. Int J Mol Sci 2019;20:4931.

86 Bianco A, Malapelle U, Rocco D, et al. Targeting immune checkpoints in non small cell lung cancer. Curr Opin Pharmacol 2018;40:46-50.

87 Perrotta F, Rocco D, Vitiello F, et al. Immune checkpoint blockade for advanced NSCLC: a new landscape for elderly patients. Int J Mol Sci 2019;20:2258. 
88 Bianco A, Campbell SFM. Atezolizumab plus platinumbased regimen and bevacizumab: Is it time to consider immunotherapy in a concurrent approach for lung cancer? Transl Cancer Res 2018;8:S103-5. https://doi. org/10.21037/25256

89 Fiorelli A, Vitiello F, Morgillo F, et al. Pembrolizumab monotherapy in advanced NSCLC patients with low PD-L1 expression: is there real evidence? Transl Cancer Res 2019;8(Suppl 6):S618-20. https://doi.org/10.21037/ tcr.2019.06.28

90 Mouronte- Roibas C, Leiro-Fernandez-Villa A, Botana-Rial $\mathrm{M}$, et al. COPD, emphysema and the onset of lung cancer. A systematic review. Cancer Lett 2016;382:240-4.

91 Smith BM, Pinto L, Ezer N, et al. Emphysema detected on computed tomography and risk of lung cancer: a systematic review and meta-analysis. Lung Cancer 2012;77:5863.

92 Calabrò E, Randi G, La Vecchia C, et al. Lung function predicts lung cancer risk in smokers: a tool for targeting screening programmes. Eur Respir J 2010;35:146-51. https://doi.org/10.1183/09031936.00049909

${ }_{93}$ Mark NM, Kargl J, Busch SE, et al. Chronic obstructive pulmonary disease alters immune cell composition and immune checkpoint inhibitor efficacy in non-small cell lung cancer. Am J Respir Crit Care Med 2018;197:325-36.

94 Rizvi NA, Hellmann MD, Snyder A, et al. Cancer immunology. Mutational landscape determines sensitivity to PD-1 blockade in non-small cell lung cancer. Science 2015;348:124-8. https://doi.org/10.1126/science.aaa1348

95 Perrotta F, Cennamo A, Cerqua FS, et al. Effects of a high-intensity pulmonary rehabilitation program on the minute ventilation/carbon dioxide output slope during exercise in a cohort of patients with COPD undergoing lung resection for non-small cell lung cancer. J Bras Pneumol 2019;45:e20180132. https://doi.org/10.1590/1806-3713/ e20180132

96 Salvi R, Meoli I, Cennamo A, et al. Preoperative highintensity training in frail old patients undergoing pulmonary resection for NSCLC. Open Med (Wars) 2016;11:443-8. https://doi.org/10.1515/med-2016-0079

97 Moyer VA. Screening for lung cancer: U.S. Preventive Services Task Force recommendation statement. Ann Intern Med 2014;160:330-8.

98 De Torres JP, Wilson DO, Sanchez-Salcedo P, et al. Lung cancer in patients with chronic obstructive pulmonary disease. Development and validation of the COPD Lung Cancer Screening score. Am J Resir Crit Care Med 2015;191:285-91.

99 Young RP, Duan F, Chiles C, et al. Airflow limitation and histologu shift in the National lung screening trial. The NLST-ACRIN Cohort Substudy. Am J Respir Crit Care Med 2015;192:1060-7.

100 De Torres JP, Casanova C, Marin JM, et al. Exploring the impact of screening with low-dose CT on lung cancer mortality in mild to moderate COPD patients: a pilot study. Respir Med 2013;107:702-7.

101 Young RP, Hopkins RJ. Measures of outcome in lung cancer screening: maximising the benefits. $J$ Thorac Dis 2016;8:e1317-20.

102 Hudgel DW, Martin RJ, Johnson B, et al. Mechanics of the respiratory system and breathing pattern during sleep in normal humans. J Appl Physiol Respir Environ Exerc Physiol 1984;56:133-7.

${ }^{103}$ Mollica M, Nicolai A, Maffucci R. Obstructive sleep apnea and cardiovascular risks in the elderly population. Journal of Gerontology and Geriatrics 2018;66:149-55.

104 Collop N. Sleep and sleep disorders in chronic obstructive pulmonary disease. Respiration 2010;80:78-86.

105 Lacedonia D, Nigro E, Matera MG, et al. Evaluation of adiponectin profile in Italian patients affected by obstructive sleep apnea syndrome. Pulm Pharmacol Ther 2016;40:1048. https://doi.org/10.1016/j.pupt.2016.07.008

106 Machado MC, VollmerWM, Togeiro SM, et al. CPAP and survival in moderate-to-severe obstructive sleep apnoea syndrome and hypoxaemic COPD. Eur Respir J 2010;35:1327. https://doi.org/10.1183/09031936.00192008

${ }_{107}$ Marin JM, Soriano JB, Carrizo SJ, et al. Outcomes in patients with chronic obstructive pulmonary disease and obstructive sleep apnea: the overlap syndrome. Am J Respir Crit Care Med 2010;182:325-31.

108 Fletcher EC, Luckett RA, Goodnight-White S, et al. A double-blind trial of nocturnal supplemental oxygen for sleep desaturation in patients with chronic obstructive pulmonary disease and a daytime $\mathrm{PaO} 2$ above $60 \mathrm{~mm} \mathrm{Hg}$. Am Rev Respir Dis 1992;145:1070-6.

109 Patil SP, Ayappa IA, Caples SM, et al. Treatment of adult obstructive sleep apnea with positive airway pressure: an American Academy of Sleep Medicine Clinical Practice Guideline. J Clin Sleep Med 2019;15:335-43.

110 Cederholm T, Barazzoni R, Austin P, et al. ESPEN guidelines on definitions and terminology of clinical nutrition. Clin Nutr 2017;36:49-64. https://doi.org/10.1016/j. clnu.2016.09.004

${ }_{111}$ Cruz-Jentoft AJ, Baeyens JP, Bauer JM, et al. Sarcopenia: European consensus on definition and diagnosis: report of the European working group on sarcopenia in older people. Age Ageing 2010;39:412-23. https://doi.org/10.1093/ ageing/afq034

112 Janssen I, Baumgartner RN, Ross R, et al. Skeletal muscle cutpoints associated with elevated physical disability risk in older men and women. Am J Epidemiol 2004;159:413-21.

${ }_{113}$ Ling $\mathrm{CH}$, Taekema D, de Craen AJ, et al. Handgrip strength and mortality in the oldest old population: the Leiden 85-plus study. CMAJ 2010;182:429-35. https://doi. org/10.1503/cmaj.091278

114 Kon SS, Patel MS, Canavan JL, et al. Reliability and validity of 4-metre gait speed in COPD. Eur Respir J 2013;42:33340. https://doi.org/10.1183/09031936.00162712

${ }^{115}$ De Blasio F, Di Gregorio A, De Blasio F, et al. Malnutrition and sarcopenia assessment in patients with chronic obstructive pulmonary disease according to international diagnostic criteria, and evaluation of raw BIA variables. Respir Med 2018;134:1-5.

${ }^{116}$ De Blasio F, Scalfi L, Di Gregorio A, et al. Raw 
bioelectrical impedance analysis variables are independent predictors of early all-cause mortality in patients with COPD. Chest 2019;155:1148-57. https://doi.org/10.1016/j. chest.2019.01.001

117 De Blasio F, Santaniello MG, de Blasio F, et al. Raw BIA variables are predictors of muscle strength in patients with chronic obstructive pulmonary disease. Eur J Clin Nutr 2017;71:1336-40. https://doi.org/10.1038/ejcn.2017.147

118 De Blasio F, de Blasio F, Miracco Berlingieri G, et al. Evaluation of body composition in COPD patients using multifrequency bioelectrical impedance analysis. Int J Chron Obstruct Pulmon Dis 2016;11:2419-26.

${ }^{119}$ Luo Y, Zhou L, Li Y, et al. Fat-free mass index for evaluating the nutritional status and disease severity in COPD. Respir Care 2016;61:680-8. https://doi.org/10.4187/respcare.04358

120 Jones SE, Maddocks M, Kon SS, et al. Sarcopenia in COPD: prevalence, clinical correlates and response to pulmonary rehabilitation. Thorax 2015;70:213-8. https://doi. org/10.1136/thoraxjnl-2014-206440

121 Gan WQ, Man SF, Senthilselvan A, et al. Association between chronic obstructive pulmonary disease and systemic inflammation: a systematic review and a meta-analysis. Thorax 2004;59:574-80.

122 Byun MK, Cho EN, Chang J, et al. Sarcopenia correlates with systemic inflammation in COPD. Int J Chron Obstruct Pulmon Dis 2017;12:669-75.

123 Barnes PJ, Celli BR. Systemic manifestations and comorbidities of COPD. Eur Respir J 2009;33:1165-85.

${ }^{124}$ Carbó N, Busquets S, van Royen M, et al. TNF-alpha is involved in activating DNA fragmentation in skeletal muscle. Br J Cancer 2002;86:1012-6.

125 Takabatake N, Nakamura H, Abe S, et al. The relationship between chronic hypoxemia and activation of the tumor necrosis factor-alpha system in patients with chronic obstructive pulmonary disease. Am J Respir Crit Care Med 2000;161:1179-84.

${ }^{126}$ De Theije C, Costes F, Langen RC, et al. Hypoxia and muscle maintenance regulation: implications for chronic respiratory disease. Curr Opin Clin Nutr Metab Care 2011;14:548-53.

127 Visser M, Schaap LA. Consequences of sarcopenia. Clin Geriatr Med 2011;27:387-99.

${ }^{128}$ Cruz-Jentoft AJ, Bahat G, Bauer J et al. Sarcopenia: revised European consensus on definition and diagnosis. Age Ageing 2019;48:16-31.

129 Ferreira IM, Brooks D, White J, et al. Nutritional supplementation for stable chronic obstructive pulmonary disease. Cochrane Database Syst Rev 2012;12:Cd000998.

130 Bauer J, Biolo G, Cederholm T, et al. Evidence-based recommendations for optimal dietary protein intake in older people: a position paper from the PROT-AGE Study Group. J Am Med Dir Assoc 2013;14:542-59.

131 Kuchuk NO, Pluijm SM, van Schoor NM, et al. Relationships of serum 25-hydroxyvitamin $D$ to bone mineral density and serum parathyroid hormone and markers of bone turnover in older persons. J Clin Endocrinol Metab 2009;94:1244-50.

132 Molfino A, Gioia G, Rossi Fanelli F, et al. Beta-hydroxy-beta-methylbutyrate supplementation in health and disease: a systematic review of randomized trials. Amino Acids 2013;45:1273-92.

133 Corbi G, ContiV, Troisi J, etal. Cardiac rehabilitation increases SIRT1 activity and $\beta$-hydroxybutyrate levels and decreases oxidative stress in patients with HF with preserved ejection fraction. Oxid Med Cell Longev 2019;2019:7049237. https://doi.org/10.1155/2019/7049237

134 Dalton JT, Taylor RP, Mohler ML, et al. Selective androgen receptor modulators for the prevention and treatment of muscle wasting associated with cancer. Curr Opin Support Palliat Care 2013;7:345-51.

135 Graat-Verboom L, Wouters EF, Smeenk FW, et al. Current status of research on osteoporosis in COPD: a systematic review. Eur Respir J 2009;34:209-18.

136 Ohara T, Hirai T, Muro S, et al. Relationship between pulmonary emphysema and osteoporosis assessed by CT in patients with COPD. Chest 2008;134:1244-9.

137 Van Staa TP, Leufkens HG, Cooper C. The epidemiology of corticosteroid-induced osteoporosis: a meta-analysis. Osteoporos Int 2002;13:777-87.

138 Walsh LJ, Wong CA, Oborne J, et al. Adverse effect of oral corticosteroids in relation to dose in patients with lung disease. Thorax 2001;56:279-84.

139 Langhammer A, Forsmo S, Syversen U. Long-term therapy in COPD: any evidence of adverse effect on bone? Int J Chron Obstruct Pulmon Dis 2009;4:365-80.

140 Ferguson GT, Calverley PM, Anderson JA, et al. Prevalence and progression of osteoporosis in patient with COPD: results from the TOwards a Revolution in COPD health study. Chest 2009:136:1456-65.

${ }_{141}$ Tang BM, Eslick GD, Nowson C, et al. Use of calcium or calcium in combination with vitamin $\mathrm{D}$ supplementation to prevent fractures and bone loss in people aged 50 years and older: a meta-analysis. Lancet 2007;370:657-66.

142 Smith BJ, Laslett LL, Pile KD, et al. Randomized controlled trial of alendronate in airways disease and low bone mineral density. Chron Respir Dis 2004;1:131-7. 